\title{
Ações afirmativas no direito brasileiro
}

\author{
Affirmative actions in brazilian law \\ Acciones afirmativas en la ley brasileña
}

Recebido: 11/06/2021 | Revisado: 16/06/2021 | Aceito: 17/06/2021 | Publicado: 19/06/2021

\author{
Thayanny Teixeira Santos \\ ORCID: https://orcid.org/0000-0003-2858-061X \\ Advogada, Brasil \\ E-mail: thayanny.santos.adv@gmail.com
}

\begin{abstract}
Resumo
A discriminação social é algo recorrente na sociedade brasileira, acarretando deste modo, uma grande desigualdade com relação a grupos mais desfavorecidos e marginalizados, desde os tempos pretéritos. Diante disso, o presente artigo faz uma análise das ações afirmativas no Brasil e sua aplicabilidade, como meio de demonstrar a importância desse instituto no combate às desigualdades tão enraizadas socialmente. Com isso, será abordado a evolução histórica, e o conceito das ações afirmativas, especialmente no âmbito brasileiro. Em seguida, será enfatizado o princípio e direito fundamental da igualdade, bem como a admissão do instituto das ações afirmativas pela Constituição da República Federativa de 1988. Por fim, será demonstrado também, qual posicionamento adotado pelo Supremo Tribunal Federal acerca do referido tema. Para tanto, o método adotado é o dedutivo, utilizando-se abordagem histórica, doutrinária, jurisprudencial e de artigos referentes ao conteúdo. Como resultados obtidos, destaca-se que as ações afirmativas são respaldadas pela Constituição Federal, como forma de garantir a igualdade.
\end{abstract}

Palavras-chave: Ações afirmativas; Desigualdade social; Discriminação; Princípio da igualdade; Constituição Federal.

\begin{abstract}
Social discrimination is something that is recurrent in Brazilian society, thus causing a great inequality in relation to the most disadvantaged and marginalized groups, from the past times. In light of this, this article analyzes affirmative actions in Brazil and their applicability, as a means of demonstrating the importance of this institute in combating inequalities so deeply rooted socially. With this, the historical evolution and the concept of affirmative actions will be approached, especially in the Brazilian context. Then, the fundamental principle and right of equality will be emphasized, as well as the admission of the affirmative action institute by the 1988 Federal Constitution. Finally, it will also be attributed which position adopted by the Supreme Federal Court on the subject. For that, the method adopted is the deductive one, using historical, doctrinal, jurisprudential and articles referring to the content approach. As outstanding results, it is noteworthy that affirmative actions are supported by the Federal Constitution, as a way of guaranteeing equality.
\end{abstract}

Keywords: Affirmative actions; Social inequality; Discrimination; Principle of equality; Federal Constitution.

\section{Resumen}

La discriminación social es algo recurrente en la sociedad brasileña, provocando, de esta manera, una gran desigualdad en relación a los grupos más desfavorecidos y marginados, desde tiempos pasados. Por ello, este artículo analiza la acción afirmativa en Brasil y su aplicabilidad, como un medio para demostrar la importancia de este instituto en la lucha contra las desigualdades tan arraigadas en la sociedad. Con esto, se abordará la evolución histórica y el concepto de acción afirmativa, especialmente en el contexto brasileño. Posteriormente, se enfatizará el principio y derecho fundamental de la igualdad, así como la admisión del instituto de acciones afirmativas por la Constitución de la República Federativa de 1988. Finalmente, también se demostrará qué posición adoptó la Corte Suprema sobre la sujeto. Para ello, el método adoptado es el deductivo, utilizando un abordaje del contenido histórico, doctrinal, jurisprudencial y de artículos relacionados. Como resultados obtenidos, se destaca que las acciones afirmativas están respaldadas por la Constitución Federal, como una forma de garantizar la igualdad.

Palabras clave: Acciones afirmativas; Desigualdad social; Discriminación; Principio de igualdad; Constituicion Federal.

\section{Introdução}

O presente trabalho tem como objetivo analisar o instituto das ações afirmativas e sua aplicabilidade no Brasil, bem como, demonstrar se ocorre compatibilização com relação a Constituição Federal de 1988, especialmente, com o princípio da 
igualdade material, de modo a evidenciar que as ações afirmativas são imprescindíveis para combater as desigualdades existentes numa sociedade totalmente preconceituosa e excludente, desde os tempos mais remotos e nos diversos setores sociais, seja na ceara educacional, empregatícia, criminal, prisional, etc.

Atinente a isso, a problemática referente a temática abordada será sobre a possibilidade da implementação de ações afirmativas no âmbito brasileiro, sob a égide dos aspectos estruturantes e princípios da referida Constituição, especialmente com relação a igualdade material. Com efeito, para essa questão, entende-se que a Carta Magna do Brasil recepciona e promove medidas positivas e discriminatórias, com intuito de consagrar a igualdade material, por intermédio da mudança social, que é necessária para efetivação da proteção da dignidade da pessoa humana.

Nesse diapasão, o tema se faz pertinente, tendo em vista as variadas polêmicas que o circunda, uma vez que muitas pessoas, por diversos motivos, são contra a promoção de políticas públicas em benefício de grupos menos favorecidos, defendendo até a ilegitimidade das medidas afirmativas.

O primeiro capítulo, busca apresentar a evolução histórica e o conceito das ações afirmativas, suas características e objetivos primordiais, especialmente no contexto brasileiro.

O segundo capítulo, será abordado um estudo dos fundamentos e objetivos da Constituição Federal de 1988, com ênfase na dignidade da pessoa humana e na realização da igualdade material. Além de abordar a possibilidade das ações afirmativas sob o viés da constituição de 1988.

A seguir, no terceiro capítulo, será feito um estudo sobre o posicionamento do Supremo Tribunal Federal, com relação as medidas afirmativas, uma vez que o mesmo é considerado o protetor da Constituição. Por fim, na conclusão, ressalta-se a importância das ações afirmativas no combate à discriminação e também confirma a sua constitucionalidade, principalmente quando se trata da consolidação da igualdade social.

\section{Metodologia}

A metodologia adotada para o presente artigo foi o método dedutivo, que pressupõe que a única forma de alcançar o conhecimento verdadeiro é por meio da razão, ou seja, através do processo de análise e raciocínio das informações, para se chegar até uma conclusão, um resultado final. Este método é proposto pelos racionalistas, como por exemplo, Descartes, Spinoza, Leibniz, entre outros (Gil, 2008, p.10).

Além disso, foi utilizado também no presente artigo a pesquisa qualitativa que se caracteriza em princípio, por não utilizar instrumento estatístico na análise dos dados (Viera \& Zouain, 2006; Bardin, 2011). Razão pelo qual, tem como objetivo entender, descrever e explicar os fenômenos sociais de modo diversificados, através de análises de experiências, sejam individuais ou grupais, bem como, pelo exame de interação e comunicações que estejam se desenvolvendo, assim como da investigação de documentos (textos, imagens, filmes ou músicas) ou traços semelhantes de experiências e integrações (Flick, 2009).

Para tanto, no referido artigo a abordagem histórica se fez imprescindível, uma vez que os estudos de natureza sócio histórica, nos permite compreender os diferentes grupos humanos e o seu cotidiano em cada espaço temporal correspondente. Sendo assim, um dos objetivos da investigação histórica é investigar sobre o passado, de maneira que as ações do presente, possam ser esclarecidas, e contribuam, inclusive, para percepção de algumas questões futuras.

Ademais, também será inegável a utilização bibliográfica (estudo da doutrina brasileira) neste artigo, oferecendo embasamento teórico e metodológico, realizados através das leituras, fichamentos e análises das obras escolhidas, de modo a complementar as investigações realizadas, com a finalidade de contribuir com o estudo do tema selecionado e como uma forma de buscar por soluções para o problema elaborado no projeto de pesquisa.

No mais, também foi utilizado análise jurisprudencial para retratar as variadas posições sobre o tema e a posição mais 
atual das Cortes. Por último, e não menos importante, como objeto de pesquisa foi adotado também artigos referentes ao conteúdo, para auxiliar na conclusão.

\section{Ações Afirmativas e Seus Principais Pontos}

Incontestavelmente, a discriminação e a desigualdade social fazem parte da história da sociedade, razão pelo qual, fezse necessário uma participação estatal mais ativa, por intermédio da adoção de medidas eficazes no combate dessa situação, como forma de resguardar a dignidade da pessoa humana e seus direitos fundamentais.

Assim, o Estado decidiu utilizar das ações afirmativas, para buscar pela igualdade material, uma vez que esse instituto pode ser considerado um legítimo remédio para corrigir as injustiças historicamente ocorridas na sociedade.

Deste modo, o objeto desse capítulo será ação afirmativas e seus principais pontos, tais como evolução histórica e seu conceito no contexto brasileiro.

\subsection{Evolução Histórica}

A origem das ações afirmativas ocorreu na Índia, país esse visivelmente marcado por uma enorme diversidade étnicoracial e cultural, o que consequentemente gerou uma discrepante desigualdade social naquele país. Com isso, motivados a combater essa situação, sobremaneira da exclusão social, lideranças políticas indianas poderosas aprovaram, no ano de 1935, o chamado Government of India Act, documento que tinha como intuito à inclusão social das camadas vulneráveis (Menezes, 2001).

Contudo, aduz Bertoncini e Filho (2012), que foi nos Estados Unidos o local onde a nomenclatura "ação afirmativa" ("affirmative action") foi usada pela primeira vez, em 1960, num período marcado pela busca da igualdade de condições entre os negros estadunidenses.

Como bem Salientam, Bertoncini e Filho (2012, p. 406): "Recuperando o foco da gênese das políticas de ação afirmativa, ao tempo da concepção da Constituição Federal dos Estados Unidos, passava o país por um intenso movimento que buscava a abolição da escravatura. Os escravos negros ainda eram considerados objetos de direito e não sujeitos de direito".

No ano de 1961, o presidente John Kennedy editou a norma executiva $n^{\circ} 10.952$, norma essa que de acordo com Rodrigues (2005), vedava pela primeira vez expressões que discriminava (raça e nacionalidade) a candidatos à vaga de emprego no âmbito da administração pública.

Entretanto, foi nas reivindicações dos negros na luta para obterem direitos civis, que podemos ressaltar o movimento mais forte até aquele momento das ações afirmativas. Tendo em vista que, foram anos e mais anos que os Estados Unidos se manteve centro de inúmeras e graves situações discriminatórias contra os negros, marginalizados social e economicamente, até mesmo pelas próprias leis americanas, que os colocavam em situações vexatórias, os inibindo de seus direitos fundamentais.

Entre os chamados "movimentos negros", podem ser citados dois de grande relevância. O primeiro é o movimento pacífico liderado por Martin Luther King, e o segundo é movimento mais radical das "Panteras Negras", que encontrou na força das armas a resposta à discriminação da população negra (Rodrigues, 2005).

Nesse cenário, a Marcha para Washington, em 1963, liderada por Martin Luther King, foi crucial para que fosse aprovada o Civil Rights Act de 1964 (Lei dos Direitos Civis), ou seja, os direitos civis foram reconhecidos à população negra, pelo então presidente Lyndon Johnson, antigo vice-presidente dos Estados Unidos. (Rodrigues, 2005).

Contudo, conforme Menezes (2001), a participação do presidente Johnson não foi limitada à aprovação da Lei dos Direitos Civis, uma vez que infelizmente o resultado das de tal aprovação foi insatisfatório, não ocasionando em grandes mudanças na questão da igualdade. Razão pelo qual, no de 1965, Lyndon Johnson proclamou na Universidade de Howard o seguinte discurso: 
Você não pega uma pessoa que durante anos esteve acorrentada e a libera, e a coloca na linha de partida de uma corrida e diz: 'você está livre para competir com todos os outros', e ainda acredita, legitimamente, que foi totalmente justo. Assim, não é suficiente apenas abrir os portões da oportunidade; todos os nossos cidadãos devem ter a capacidade de atravessar esses portões (Menezes, 2001, p. 91).

Deste modo, o trecho acima evidencia que a igualdade quando apenas formal, adota um tratamento igual a todos, sem ter atenção as particularidades de cada situação, o que faz com que ela deixe de ser eficaz em decorrência das desigualdades apresentadas. Por isso, para se realizar verdadeira justiça social, é imprescindível que tratamentos especiais sejam concedidos as pessoas que sempre tiveram em situação de vulnerabilidade e inferioridade, para que assim possam competir de igual para igual com os demais.

No ano de 1965, foi promulgada a Ordem Executiva n ${ }^{\circ} 11.246$, que exigia das empresas que fossem contratar com a Administração Pública que atuassem a favor da diversidade e com a integração de minorias excluídas socialmente e discriminadas historicamente, o que contribuiu que a expressão affirmative action se consolidasse nesse momento (Rodrigues, 2005).

Vemos assim, que juntamente com às políticas de combate à discriminação, se fez presente as políticas de inclusão social, econômica e política, para que surgisse as medidas verdadeiramente voltadas à promoção de uma igualdade entre os indivíduos, independentemente de sua cor, origem, gênero ou raça, (Piovesan, 2008).

Nesta evolução histórica, houve o momento, o qual a Suprema Corte dos Estados Unidos, por ocasião do julgamento do caso Regents of The University of California v. Bakke (1978), chegou a questionar as ações afirmativas e sua legitimidade, concluindo assim que as mesmas eram medidas constitucionalmente reconhecidas como dispositivos legítimos contra à discriminação.

Gomes observa que as ações afirmativas, além de ser um instrumento garantidor de equidade, também trouxe várias beneficies para comunidade Norte Americana, como bem explicitado nos estudos realizados pela Universidade de Harvard:

[...] os avanços obtidos pelos negros norte-americanos na área da educação, em consequência das ações afirmativas, são simplesmente impressionantes, sobretudo, se levarmos em conta o fato de que, até o início dos anos 60, os negros eram proibidos de frequentar os mesmos locais públicos, as mesmas escolas, os mesmos locais de diversão frequentados pelos brancos. O mencionado estudo revela, por exemplo, que o percentual de negros formados em Universidades e escolas profissionais pulou, entre 1960 e 1995, de 5,4\% para $15,5 \%$ do total de graduados; nas faculdades de Direito, o progresso de $1 \%$ para $7,55 \%$, ou seja, mais de $700 \%$; em medicina, de $2,2 \%$ em 1964, para 8,1\% em 1995; as empresas americanas em geral, que, no início dos anos 60, não tinham negros em cargos executivos (como no Brasil do ano 2000), atualmente abrigam $8 \%$ de negros nas posições de executivos e administradores; o número total de agentes públicos eleitos (governadores, prefeitos, delegados, juízes e promotores, xerifes, etc.) passou entre 1965 e 1995 de 280 para 7.984 (Gomes, 2001, p. 91).

Como se pode ver, as ações afirmativas trás efeitos satisfatórios para os países que se importam em buscar a justiça social e o respeito pela dignidade da pessoa humana, devido a isso, muitas constituições passaram a promulgar essas medidas. Como por exemplo, a Constituição brasileira.

\subsection{Origem E A História Das Ações Afirmativas No Contexto Brasileiro}

De antemão, é cabível ressaltar que a discriminação de minorias étnicas, afrodescendentes, pardos, índios, mulheres e pessoas com deficiência é um fato que persiste desde muito tempo até os dias atuais, em todo o mundo, não sendo diferente na sociedade brasileira. Para o Ministro Joaquim Barbosa:

[...] a discriminação, como componente indissociável do relacionamento entre os seres humanos, reveste-se de uma roupagem competitiva. O que está em jogo aqui é, em certa medida, competição: é o espectro competitivo que 
germina em todas as sociedades. Quanto mais intensa a discriminação e mais poderosos os mecanismos inerciais que impedem o seu combate, mais ampla se mostra a clivagem entre o discriminador e o discriminado (Gomes, 2001).

Devido a isso, tornou-se claro, porém, a necessidade de os Estados adotarem medidas para minimizar esse comportamento retrogrado social, em busca da aplicação da igualdade material. Sendo, as primeiras normas editadas, as que proibiam práticas discriminatórias baseadas em critérios de origem, raça, sexo, cor e idade, normas esses referentes ao ordenamento jurídico franco-germânicos, quais sejam as normas decorrentes do preâmbulo da Constituição francesa e da Constituição alemã, copiadas posteriormente nas constituições de outros países, inclusive na constituição brasileira.

Embora Ferreira Filho (2003) sustente que as ações afirmativas no Brasil ganharam maior expressão em decorrência da implementação das cotas no processo seletivo das universidades públicas, é notório que desde o ano de 2001, o Estado já se mostrava interessado na criação de textos positivados, voltados à solidificação da igualdade de oportunidades do seu povo.

Consoante, Santos et al. (1999), as ações afirmativas no contexto nacional, foi registrada pela primeira vez em 1968, quando o Tribunal Superior do Trabalho na tentativa de diminuir desigualdades reservou uma porcentagem mínima nas empresas para empregados negros $(20 \%, 15 \%$ ou $10 \%)$, de acordo com o ramo e demanda da atividade desempenhada, contudo essa tentativa não obteve êxito. Em seguida, houveram-se outras tentativas de implementação de políticas públicas afirmativas, mas também restaram infrutíferas.

Ocorre, porém, que as medidas afirmativas só foram efetivadas depois de promulgada a Constituição Federal, democrática e social de 1988, que trouxe inovações com relação à proteção ao mercado de trabalho da mulher, bem como a reserva de percentual de cargos e empregos públicos para pessoas deficientes, como bem salienta o artigo $7^{\circ}$, XXXI, que proíbe qualquer discriminação referente a salário e critério de admissão de trabalhador portador de deficiência. Acrescenta-se ainda artigo 24, XIX, que alega a competência da União, dos Estados e do Distrito Federal, legislar concorrentemente sobre a proteção e integração social das pessoas portadoras de deficiência.

Denota-se do corpo do dispositivo constitucional a inclusão do artigo 37, VIII da Carta Magna, que dispõe pela lei a reserva de percentual dos cargos e empregos públicos para as pessoas portadoras de deficiência e seus critérios admissão. Além disso, a Lei Federal 7.853/89, conjuntamente com o Decreto Federal 3.298 de 20 de dezembro de 1999 que a regulamentou, normatizou a acessibilidade.

É notório ressaltar, que essas mudanças só ocorreram por intermédio da evolução da legislação internacional, como os tratados e convenções dos quais o Brasil era signatário, inclusive no ano de 1981 foi proclamado pela Organização das Nações Unidas o Dia Internacional das Pessoas Deficientes.

Outro ponto digno de nota, é que a década de 1990 se tornou o começo das mudanças referentes a luta contra a discriminação racial, étnica, de gênero, dentre outras. Como por exemplo as Leis 8.112/90, art. $5^{\circ}$, § $2^{\circ}$ e a Lei 8.213/91, art. 93 que reserva até $20 \%$ de cotas para os portadores de deficiências no serviço público civil da União e no setor privado, respectivamente (Moehlecke, 2002).

Pode ser destacado também, a Marcha Zumbi dos Palmares contra o Racismo, no ano de 1995 em Brasília, onde o movimento negro brasileiro, juntamente com centrais sindicais, reuniu por volta de 30.000 pessoas, para reivindicar e formular e a implantação de políticas públicas em benefício dos negros, para deste modo, tentar superar a discriminação racial, sendo o movimento de maior pressão e aproximação da popular com o Poder Público (Santos, 1999).

Além disso, no dia 20 de novembro de 1995 foi instituído, por meio de decreto, o chamado Grupo de Trabalho Interministerial GTI, com o intuito de desenvolver políticas que valorizassem a promoção da população negra com estabelecimento de incentivos fiscais às empresas que adotassem programas e projetos relativos à busca pela igualdade racial (Moehlecke, 2002).

Já em 1996, foi criado o Programa Nacional dos Direitos Humanos (PNDH), que tinha como escopo a criação de 
ações afirmativas que incentivassem o acesso dos negros a cursos profissionalizantes, ao ensino superior, bem como, nas áreas tecnológicas (Brasil, 1996).

Em seguida, no ano de1997, foi promulgada a Lei 9.504/97, que em seu art. 10, $\S 3^{\circ}$, determinava uma cota mínima de $30 \%$ de mulheres para as candidaturas de todos os partidos políticos, fato esse reconhecido como a primeira política de cotas adotada em nível nacional (Santos, 1999). No entanto, foi a partir de 2001 que as políticas de ação afirmativa correspondentes às diversas camadas da população pertencentes aos setores minoritários passaram a ser aprovadas mais efetivamente.

No plano da discriminação racial, ensina o autor Lima (2010), a "Conferência Mundial contra o Racismo, a Discriminação Racial e a Xenofobia e Formas Correlatas de Intolerância”, sediada na África do Sul em 2001, é considerada o panorama inicial para a inclusão efetiva do tema racial na agenda do governo:

O Brasil teve uma participação de grande destaque tanto nas reuniões Preparatórias como na própria Conferência. Embora muitos projetos já estivessem delineados e alguns deles sendo implantados, a posição oficial do Brasil na Conferência, principalmente em relação às ações afirmativas, trouxe mudanças significativas. As áreas de saúde, educação e trabalho foram os temas prioritários nas recomendações do governo brasileiro (Lima, texto digital).

Adiante, em 2002, através da instituição do Programa Nacional de Ações Afirmativas (Decreto no 4.228), criado principalmente para proteção dos afrodescendentes, das mulheres e dos portadores de deficiência as ações afirmativas ganharam mais força. E no decorrer do referido ano também foi iniciado o Programa Diversidade na Universidade, por meio da Lei $\mathrm{n}^{\circ} 10.558 / 02$, cujo objetivo era incentivar o acesso de pessoas pertencentes a grupos socialmente minoritários, de modo especial dos afrodescendentes, o acesso ao ensino superior. Posteriormente, no ano de 2003, foi instituída a Política Nacional de Promoção da Igualdade Racial (Decreto nº 4.886/2003), focada unicamente aos negros (Moehlecke, 2002).

No cenário educacional, surge o ProUni (Programa Universidade para Todos), criado em 2004 pela Lei ${ }^{\circ}$ 11.096/2005, considerado uma das políticas afirmativas de maior significado em âmbito Federal. Esse programa consiste na concessão de bolsas de estudos em universidades privadas a alunos que cursaram o ensino médio completo em escolas públicas ou particulares como bolsistas integrais, e desde que pertençam a família com renda familiar per capita de três salários mínimos, além de ter realizado o ENEM (Exame Nacional do Ensino Médio). O programa atribui também cotas das bolsas para pardos, indígenas, negros, e pessoas com deficiência.

Corroborando com a ideia, Lima (2010) entende que todos esses programas e projetos são de extrema importância para o crescimento do nosso país, uma vez que se responsabiliza pela manutenção de privilégios de classe, do pouco e atrasado investimento tardio na educação e do desigual acesso à estrutura de oportunidades. Sendo assim, conforme o autor, o governo brasileiro está se preocupando, cada vez mais com as questões sociais atreladas à desigualdade, incluindo em sua agenda a promoção das ações afirmativas.

\subsection{Conceito De Ação Afirmativa}

Como se pode ver, a discriminação e as desigualdades socias sempre estiveram presentes no dia a dia na sociedade, o que implicou para o Estado uma atuação mais ativa, por intermédio de adoção de medidas eficientes na luta contra essa realidade injusta a qual vivemos, com a finalidade de assim garantir a proteção dos direitos humanos, dos direitos fundamentais e da dignidade da pessoa humana.

Portanto, o Estado na busca pela igualdade material tem como uma possível solução dos problemas abordados acima, a promoção das ações afirmativas, instrumentos legítimos de correção das injustiças historicamente acumuladas na sociedade. Tendo em vista que a discriminação pode ser expressa mediante distinção, exclusão, restrição e preferência de raça, cor, 
descendência ou origem nacional ou étnica que tenha o propósito ou o efeito de anular ou prejudicar o reconhecimento, gozo ou exercício de direitos humanos de maneira igualitária, bem como das liberdades fundamentais nos campos político, econômico, social, cultural ou em qualquer outro campo do contexto social.

Para tanto, as ações afirmativas são definidas como políticas ou programas, públicos ou privados, que tem como intuito conceder algum tipo de benefício a minorias ou grupos sociais que se encontrem em condições de desvantagem na vida pública, em decorrência de discriminações, atuais ou pretéritas, como as pessoas portadores de deficiência, índios, mulheres e negros.

Outra não é a linha de pensamento de Gomes que afirma que:

[...] as ações afirmativas podem ser definidas como um conjunto de políticas públicas e privadas de caráter compulsório, facultativo ou voluntário, concebidas com vistas ao combate à discriminação racial, de gênero, por deficiência física e de origem nacional, bem como para corrigir ou mitigar os efeitos presentes da discriminação praticada no passado, tendo por objetivo a concretização do ideal de efetiva igualdade de acesso a bens fundamentais como a educação e o emprego (Gomes, 2003, p. 27)

Importa destacar, que embora as ações afirmativas sejam conhecidas também como "políticas" porque elas têm início após a formulação de decisões, a partir da verificação e priorização de problemas sociais que requerem devida atenção e uma busca por uma solução, tais como planejamentos, programações, dentre outros (Prudente, 2003). As mesmas não se confundem com ação estatal, visto que programas desenvolvidos por particulares podem partilhar o mesmo escopo de superação de desigualdade.

Razão pelo qual as ações afirmativas, podem ser conhecidas também como políticas de discriminação reversa, pois impõem ao Estado o dever de intervir para modificar o meio social (status quo), reconhecendo quais os efeitos perversos, e os fatores discriminatórios em nossa sociedade, para que possa assim criar e executar políticas que incentivem oportunidades de inclusão social àqueles que dela necessitam (Bertoncini \& Filho, 2012).

Esses mesmos autores, evidenciam que as ações afirmativas não possuem natureza punitiva e nem tem como finalidade a proibição da discriminação, mas sim de tentar combater os efeitos deixados pela mesma, através de uma atuação positiva por parte do Estado.

É cabível ressaltar, que o instituto das ações afirmativas engloba tantas medidas impositivas (obrigatórias ou compulsórias) por parte do Estado, como de atividades voluntário-facultativas de inclusão, empregadas a critério de cada instituição (como é o caso das universidades ou empresas), seja espontaneamente ou através de incentivo do governo, mas almejando, sempre, a consagração da equidade material (Brito filho, 2014).

Importante compreender o apontamento de Piovesan (2008), sobre as ações afirmativas (também denominadas "ações compensatórias" ou "discriminação positiva"), pois segundo ela são políticas (públicas ou privadas) de caráter compensatório, promovidas para atenuar as péssimas condições sociais decorrentes de um histórico social discriminatório (por motivos raciais, étnicos, religiosos, de gênero e outros), que visam assegurar a diversidade e a pluralidade social, observados o direito à igualdade e o respeito às diferenças. Por meio dessas medidas afirmativas que ocorre a transição da igualdade formal para a igualdade material ou substantiva. Para referida doutrinadora, a discriminação ocorre quando os iguais são tratados desigualmente e quando os desiguais são tratados igualmente. Por essa razão, além de proibir a discriminação, é necessária a adoção de políticas compensatórias (promocionais), que garantam a igualdade.

Outro ponto de grande relevo, foi abordado por Ferreira Filho (2003) que afirma a necessidade de as ações afirmativas serem implementadas de forma temporária, evitando-se, assim, uma eventual carga negativa de igualdade, o que desnaturaria o seu propósito. Para o autor o respeito à temporariedade é necessário para a legitimidade dessas ações, as quais devem perdurar até que se atinja, efetivamente, a igualdade material. Assim, tão logo se alcance esse propósito, a ação afirmativa criada para o 
caso específico não deve mais prosperar.

Noutro vértice, para Cruz (2011), no entanto, é equivocado deduzir que, mediante as ações afirmativas, a igualdade será sempre alcançada. Pois, conforme o autor, por vezes a igualdade material não é atingida, o que exigiria a subsistência da ação. Razão pelo qual, muitas vezes, a definição dessas medidas perde seu caráter definidor de temporariedade, tendo em vista a existência de algumas desigualdades nunca uniformizadas na sociedade.

\section{Princípio da Igualdade e a Constitucionalidade das Ações Afirmativas}

\subsection{Princípio Da Igualdade}

A atual Constituição admitiu expressamente o princípio da isonomia, como também a dignidade da pessoa humana, conforme dispõe o artigo $1^{\circ}$, inciso III da Carta da República. Denota-se do corpo do dispositivo constitucional objetivos fundamentais da República Federativa do Brasil, dos quais encontramos em seu artigo $3 .^{\circ}$, quais sejam a construção de uma sociedade livre, justa e solidária; garantia do desenvolvimento nacional; erradicação da pobreza e a marginalização, redução das desigualdades sociais e regionais, além da importância de promover o bem de todos, sem preconceitos de origem, cor, idade, raça, sexo, e quaisquer outras formas de discriminação.

Por sua vez, para garantir a efetividade desses princípios constitucionais acima explanados, o princípio da igualdade, estabelecido no caput do artigo 5. ${ }^{\circ}$ da Constituição Federal, afirma que todos são iguais perante a lei, sem distinção de qualquer natureza, garantindo-se aos brasileiros e aos estrangeiros residentes no País, a inviolabilidade do direito à vida, à igualdade, à segurança e à propriedade à liberdade. Por esse princípio não é admissível diferenciações de tratamentos arbitrários, exteriorizadas sob a forma de discriminações (situações de desvantagem) ou privilégios (situações de vantagem), conforme os conceitos de igualdade na lei, perante a lei e igualdade formal e material.

Para o princípio da igualdade na lei, a elaboração das regras jurídicas não pode consolidar desequiparações não autorizadas pela ordem constitucional, destinada principalmente ao poder legislativo. Diferentemente, do que define a igualdade perante a lei que determina que a aplicação das regras jurídicas deve ser realizada em compatibilidade com o definido pelas mesmas, ainda que resulte em desigualdades. Essa igualdade é dirigida precipuamente aos órgãos judiciais.

Adiante, também ocorre divisão entre princípio da igualdade formal, também denominada de igualdade perante a lei, civil ou jurídica, e princípio da igualdade material, também designada de igualdade na sociedade, real ou fática, já que essa tem como finalidade a igualdade efetiva perante os bens da vida, sendo uma condição da outra, pois a atribuição de direitos em paridade antecede à alteração da estrutura social e econômica, mediante a remoção de obstáculos que impeçam a sua efetiva verificação. Enquanto, aquela assegura a produção e aplicação igualitária das regras jurídicas.

Além disso, ao se analisar o caráter relativo do referido princípio, conforme Barroso (1987, p. 91) são "legítimas as desequiparações quando fundadas e logicamente subordinadas a um elemento discriminatório objetivamente aferível, que prestigie, com proporcionalidade, valores abrigados no texto constitucional", inclusive, o sistema jurídico brasileiro aborda três dos principais meios de promoção da igualdade, revestidos de natureza liberal, social e democrática.

Sem titubear, os primeiros elementos de implementação da igualdade são inerentes aos ordenamentos francogermânicos, consagrados em normas que violam a prática de discriminações baseadas em critérios de origem, sexo, cor, raça, e idade, como, por exemplo, os dispostos nos arts. $5^{\circ}$, inc. I (igualdade entre homens e mulheres), $7^{\circ}$, inc. XXX (igualdade no exercício de trabalho, ofício ou profissão ,14, caput (igualdade no valor do voto) e 37, inc. I (igualdade no acesso a cargos, empregos e funções públicas).

Em seguida, os segundos meios, intrínsecos aos ordenamentos nórdico-escandinavos, são encontrados em normas que obrigam a prestação de benefícios e serviços que atendam às necessidades básicas do ser humana, protegendo-os, assim, de determinados perigos, os quais se encontram. Exemplificando, podem ser citadas as normas consignadas nos arts. 194, 
parágrafo único, inc. II (igualdade das prestações da seguridade social), 196 (igualdade na saúde), 201, § 1 (igualdade na previdência social) e 204, caput (igualdade na assistência social), todos da Constituição da República.

Por último, os terceiros, pertencentes ao ordenamento norte-americano, são consolidados em normas que permitem a realização de ações afirmativas, uma vez que essas constituem o meio eficiente para promoção da igualdade.

Incontestavelmente as ações afirmativas têm o intuito de garantir a promulgação e a observância ao Princípio Constitucional da Igualdade, além de ser um mecanismo de aplicação e de efetivação do princípio referenciado. Entretanto, é imprescindível também que se busque a igualdade material e não apenas a igualdade formal, ou seja, é muito importante dar todos o mesmo tratamento, mas sem deixar de busca tratar desigualmente os desiguais na medida de sua desigualdade.

Adiante, frisa-se que após essas considerações, fica evidenciado o grande desafio que é a busca da igualdade material. Pois, ao mesmo tempo que o Direito tem a função de oferecer um tratamento equivalente que assegure a igualdade, o mesmo também deve oferecer um tratamento diferenciado que promova a igualdade, mas, paradoxalmente, como forma de equilibrar a sociedade da maneira mais justa na medida do possível.

\subsection{Da Possibilidade Das Ações Afirmativas Sob O Viés Da Constituição De 1988}

Releva observar que a Carta Magna brasileira goza de dispositivos que além de possibilitarem a promoção de ações afirmativas por parte do Estado e de particulares, também institui mandamentos para sua aplicação sob pena de inconstitucionalidade por omissão. No art. $5^{\circ}$, I da CF evidencia a adoção do princípio da igualdade material, a par do prestígio da igualdade formal.

Posteriormente, no seu preâmbulo, os constituintes prescreviam a instituição de um Estado Democrático de Direito, destinado a assegurar o exercício dos direitos sociais e individuais, e a promover a igualdade e a justiça como valores supremos de uma sociedade fraterna, pluralista e sem preconceitos, logo, conclui-se que o reconhecimento da existência das desigualdades compete no dever de combatê-las.

A seguir, é necessário destacar o art. $3^{\circ}$, que define os objetivos fundamentais da República Federativa do Brasil, que dispões sobre a redução das desigualdades sociais (inciso III) e regionais como a erradicação da pobreza e marginalização, de um lado, e a promoção do bem de todos, sem preconceito de origem, raça, sexo, cor, idade e quaisquer outras formas de discriminação (inciso IV). Além desses, também pode ser citado o art. 170 da Constituição que enfatiza, o objetivo de erradicação da desigualdade já manifestado nos objetivos da República no seu inciso VII.

Assinala Cruz (2005) que o artigo $3^{\circ}$ da Constituição implicitamente previu as ações afirmativas, logo que elenca como objetivo fundamental da República a promoção do bem geral, mediante a superação de preconceitos discriminatórios. Corroborando com a ideia Mello alega que o art. $3^{\circ}$ da CF legitima a implementação de ação afirmativa:

[...] A Lei Maior é aberta com o artigo que lhe revela o alcance: constam como fundamentos da República Brasileira a cidadania e a dignidade da pessoa humana, e não nos esqueçamos jamais de que os homens não são feitos para as leis; as leis é que são feitas para os homens. Do art. $3^{\circ}$ vem-nos luz suficiente ao agasalho de uma ação afirmativa, a percepção de que o único modo de se corrigir desigualdades é colocar o peso da lei, com a imperatividade que ela deve ter em um mercado desequilibrado, a favor daquele que é discriminado, que é tratado de forma desigual (Mello, 2001).

Sendo assim, pode se tirar dos ensinamentos do autor que a lei é um importante instrumento de mudança social, e por isso, o Estado tem como dever organizar o ordenamento jurídico de modo a efetivar a correção das desigualdades existentes na sociedade, porque assim o determina a Constituição, não havendo a possibilidade de qualquer omissão com relação ao tema abordado.

Nesse diapasão, Sarlet corrobora alegando que a CF impõe aos entes federados a criação e implementação de medidas 
afirmativas voltadas à uma eficiente redução das desigualdades sociais, o que implica o dever de o Poder Público adotar políticas de natureza positivamente discriminatório, “[...] cujo descumprimento poderá levar a um estado de omissão inconstitucional" (Sarlet, 2015, p. 584).

Acerca das desigualdades o constituinte explicitamente criou mandamentos específicos de legislar em favor de pessoas portadoras de deficiências físicas, para reforçar a importância desse tema e garantir-lhes uma representatividade, ainda que mínima no serviço público, como no disposto no art. 37, VIII para que, assim, surgisse uma política distributiva a fim de resgatá-los do processo histórico excludente e inseri-los num espaço de grande importância da nação.

Para corrigir a divergência dos salários no mercado de trabalho, determinou, ainda, no art. $7^{\circ}$, inciso XX, a proteção do mercado de trabalho da mulher, mediante incentivos específicos, nos termos da lei. Já para as pequenas empresas constituídas sob as leis brasileiras e que tenham sua sede e administração no País, foi estabelecido um tratamento diferente, em decorrência da sua fragilidade no mercado competitivo: o art. 170, IX, cria para o legislador ordinário o dever de favorecê-las.

Por fim, a promoção da igualdade, também tratou de estabelecer um tratamento processual mais categórico e rígido nos casos de racismo, combinando-lhe a imprescritibilidade e a insuscetibilidade de fiança.

Nas palavras de Roesler é através de instrumentos legítimos, como as ações afirmativas, que "[...] a igualdade deixa de ser apenas um princípio jurídico formalmente estabelecido na lei e passa a ser um objetivo constitucional a ser buscado pelo Estado e por toda a sociedade brasileira" (Roesler, 2010, texto digital).

Neste pressuposto, as políticas de ação afirmativa retiram seu fundamento de validade diretamente da Constituição Federal, visto que os programas dessa natureza dão plena aplicabilidade a princípios constitucionais que além de serem fundamentos da República brasileira (igualdade e dignidade da pessoa humana), também constituem direitos fundamentais (Bertoncini \& Filho, 2012, p.412).

Sob este aspecto, finalizamos dizendo que a implementação de políticas de ações afirmativas, por um legítimo Estado Democrático de Direito, como bem formalizado na Constituição Federal de 1988, não se mostra apenas possível, como, também, imprescindível à realização dos anseios constitucionais, de maneira a possibilitar a construção de uma sociedade mais igualitária, com a redução das desigualdades sociais.

\section{O Posicionamento do Supremo Tribunal Federal Diante das Ações Afirmativas}

Em verdade, o art. 102, caput, da CF, dispõe que é competência do Supremo Tribunal Federal, a proteção da Constituição, sendo ele o responsável pela observação do cumprimento e descumprimento das normas inseridas na Carta Magna. Diante dessa conjuntura, para uma melhor análise acerca das ações afirmativas perante a Lei Maior, é indispensável que se verifique, primeiramente, de que forma o Supremo Tribunal Federal se posiciona diante do tema.

A priori, a temática das ações afirmativas no Brasil concentrou-se, na década inicial do século XXI, nos debates sobre as cotas em universidades públicas, tanto em favor de negros, quanto em favor de estudantes de escolas públicas, minorias prejudicadas desde muito tempo atrás.

As reflexões acerca da questão da constitucionalidade das políticas públicas afirmativas, teve uma grande repercussão ao ser introduzida pelo Partido Democratas (DEM) quando o mesmo ajuizou, a Arguição de Descumprimento de Preceito Fundamental (ADPF) n $n^{\circ}$ 186, no ano de 2009, diante do Supremo Tribunal Federal (STF), certificando que as políticas de cotas implantadas pela Universidade de Brasília (UnB) era contrária a determinados preceitos fundamentais estabelecidos pela Constituição Federal de 1988, quais sejam, repúdio ao racismo, dignidade da pessoa humana, e o da isonomia(art. $1^{\circ}$, caput e inciso III e o art. $3^{\circ}$, IV). Isso porque para o referido partido, o mérito da questão era algo social e não racial.

Consta, entretanto, que a ADPF foi julgada improcedente pelo acórdão unânime da Suprema Corte do Brasil, pois 
entendeu ser constitucional à utilização de ações afirmativas como política necessária para a inclusão de minorias, ou seja, o sistema de cotas adotado pela UnB foi considerado constitucional, como demonstrado a seguir:

Ementa (ADPF 186) ALEGADA OFENSA AOS ARTS. $1^{\circ}$, CAPUT, III, $3^{\circ}$, IV, $4^{\circ}$, VIII, $5^{\circ}$, I, II XXXIII, XLI, LIV, 37, CAPUT, 205, 206, CAPUT, I, 207, CAPUT, E 208, V, TODOS DA CONSTITUIÇÃO FEDERAL. AÇÃO JULGADA IMPROCEDENTE. I - Não contraria - ao contrário, prestigia - o princípio da igualdade material, previsto no caput do art. $5^{\circ}$ da Carta da República, a possibilidade de o Estado lançar mão seja de políticas de cunho universalista, que abrangem um número indeterminados de indivíduos, mediante ações de natureza estrutural, seja de ações afirmativas, que atingem grupos sociais determinados, de maneira pontual, atribuindo a estes certas vantagens, por um tempo limitado, de modo a permitir-lhes a superação de desigualdades decorrentes de situações históricas particulares. II - O modelo constitucional brasileiro incorporou diversos mecanismos institucionais para corrigir as distorções resultantes de uma aplicação puramente formal do princípio da igualdade. III - Esta Corte, em diversos precedentes, assentou a constitucionalidade das políticas de ação afirmativa. [...] VII - No entanto, as políticas de ação afirmativa fundadas na discriminação reversa apenas são legítimas se a sua manutenção estiver condicionada à persistência, no tempo, do quadro de exclusão social que lhes deu origem. Caso contrário, tais políticas poderiam converter-se benesses permanentes, instituídas em prol de determinado grupo social, mas em detrimento da coletividade como um todo, situação - é escusado dizer - incompatível com o espírito de qualquer Constituição que se pretenda democrática, devendo, outrossim, respeitar a proporcionalidade entre os meios empregados e os fins perseguidos.

Para Joaquim Barbosa, único ministro negro do STF nesse julgado, exaltou a necessidade das ações afirmativas para propiciar a "harmonia e paz social". Exemplificando, que os Estados Unidos se tornaram "o país líder do mundo livre", depois do término da política de segregação racial. Segundo o Ilustre Ministro as:

\footnotetext{
“Ações afirmativas se definem como políticas públicas voltadas a concretização dos princípios constitucionais da igualdade material a neutralização dos efeitos perversos da discriminação racial, de gênero, de idade, de origem. [...] Essas medidas visam a combater não somente manifestações flagrantes de discriminação, mas a discriminação de fato, que é a absolutamente enraizada na sociedade e, de tão enraizada, as pessoas não a percebem”. (ADPF 186, Rel. Min. Joaquim Barbosa).
}

Na acepção do Ministro Ricardo Lewandowski, o relator do processo, as medidas de ações afirmativas permitem um ambiente acadêmico mais diversificado e pluralista, corrigindo assim distorções sociais perpetuadas na história. Além disso, o Ilustre Ministro destacou que essas políticas possuem um caráter transitório e devem respeitar os limites impostos pelos princípios da razoabilidade e proporcionalidade. Motivo pelo qual, defendeu a política de ação afirmativa implantada pela UnB com os valores e princípios constitucionais (ADPF 186, Rel. Min. Lewandowski, p. 46-47 do voto).

Segundo o ministro Luiz Fux a Constituição Federal exige uma reparação de danos passados do país em relação aos negros, com fundamento no artigo $3^{\circ}$, inciso I, da Constituição Federal, que dispõe como objetivo fundamental da República Federativa do Brasil, a construção de uma sociedade livre, justa e solidária (ADPF 186, Rel. Min. Lewandowski, p. 9 do voto).

Noutro vértice, a ministra Carmém Lúcia, alegou que as políticas de ação afirmativa não seriam a melhor forma de resolver o problema da desigualdade social, já que, para a ministra, “[...] a melhor opção é ter uma sociedade na qual todo mundo seja igualmente livre para ser o que quiser. Mas isto é um processo, uma etapa, uma necessidade diante de um quadro onde isso não aconteceu naturalmente" (ADPF 186, Rel. Min. Lewandowski, p. 4 do voto).

Ademais, os ministros (Rosa Werber, Joaquim Barbosa, Cezar Peluso, Gilmar Mendes, Celso de Mello, Ayres Britto e Marco Aurélio) entenderam da mesma maneira e proferiram voto pela improcedência da ADPF ajuizada.

Adiante, outra problemática que levantou uma grande pauta foram as ações afirmativas no caso da reserva de percentual de cargos e empregos públicos a portadores de deficiência: 
EMENTA: CONCURSO PÚBLICO - PESSOA PORTADORA DE DEFICIÊNCIA - RESERVA PERCENTUAL DE CARGOS E EMPREGOS PÚBLICOS (CF, ART. 37, VIII) [...] LEGITIMIDADE DOS MECANISMOS

COMPENSATÓRIOS QUE, INSPIRADOS PELO PRINCÍPIO FUNDAMENTAL DA DIGNIDADE PESSOAL (CF, ART. $1^{\circ}$, III), RECOMPÕEM, PELO RESPEITO À ALTERIDADE, À DIVERSIDADE HUMANA E À IGUALDADE DE OPORTUNIDADES, O PRÓPRIO SENTIDO DE ISONOMIA INERENTE ÀS INSTITUIÇÕES REPUBLICANAS. - O tratamento diferenciado em favor de pessoas portadoras de deficiência, tratando-se, especificamente, de acesso ao serviço público, tem suporte legitimador no próprio texto constitucional (CF, art. 37, VIII), cuja razão de ser, nesse tema, objetiva compensar, mediante ações de conteúdo afirmativo, os desníveis e as dificuldades que afetam os indivíduos que compõem esse grupo vulnerável. Doutrina. - A vigente Constituição da República, ao proclamar e assegurar a reserva de vagas em concursos públicos para os portadores de deficiência, consagrou cláusula de proteção viabilizadora de ações afirmativas em favor de tais pessoas [...] (RMS 32732 AgR, Relator(a): Min. CELSO DE MELLO, Segunda Turma, julgado em 03/06/2014, PROCESSO ELETRÔNICO DJe-148 DIVULG 31-07-2014 .PUBLIC 0108-2014). (Grifou-se).

Conforme a ementa acima, o argumento jurídico utilizado para se julgar legitimamente a reserva de percentual de cargo público a portador de deficiência, foram os princípios constitucionais da dignidade da pessoa humana e da igualdade. Bem como, o art. 37, inciso VIII, da Constituição Federal, que prevê expressamente que "a lei reservará percentual dos cargos e empregos públicos para as pessoas portadoras de deficiência e definirá os critérios de sua admissão”.

Há de se concluir, que de acordo com o STF, as políticas de ação afirmativa encontram respaldo no texto constitucional e nos seus preceitos fundamentais.

\section{Conclusão}

Diante desta conjuntura, concluímos, portanto, que apesar de anos de desigualdades e discriminações impunes, notase que o Brasil vem avançando nas últimas décadas, para acabar, ou pelo menos minimizar o sentimento de injustiça e de superioridade de uma classe sobre a outra, seja por diferenças, de cor, sexo, origem, etnia e idade, dentre outras.

Tornou-se claro, porém, que a República Federativa do Brasil se constitui de um Estado Democrático de Direito, tendo como escopo à proteção da dignidade da pessoa humana, bem como à consagração do princípio da igualdade. Devido a isso, a Constituição Federal Brasileira, dispõem em seus diversos artigos normas garantidoras para construção de uma sociedade justa livre e solidária, com instrumentos capazes de diminuir as desigualdades sociais, seja por mecanismos eficazes na promoção da igualdade material/fática (através da lei), ou por meio da igualdade formal (perante a lei) que sozinha é insuficiente para se alcançar desejos constitucionais.

É necessário frisar também, a responsabilidade do Estado de atuar ativa e positivamente em benefício das camadas minoritárias, promovendo a inclusão social e reprimindo a discriminação por motivos não justificados. Por essas razões, o pode público, deve adotar medidas de ações afirmativas, consubstanciadas em políticas públicas orientadas aos grupos vulneráveis socialmente desde muito tempo atrás.

Além disso, deve haver um trabalho intenso de conscientização da população, visto que o preconceito já está arraigado na cultura do brasileiro, até mesmo porque caso isso não ocorra, será prejudicial para própria sociedade, pois só com o fim desse comportamento preconceituoso, o Brasil poderá conseguir ser um país plenamente democrático, e materialmente igualitário.

Entretanto, enquanto isso não ocorre, uma das melhores maneiras de se combater as práticas discriminatórias e preconceituosas é por meio das ações afirmativas que deve ser utilizada como medidas temporárias, excepcionais e emergenciais, já que os brasileiros ainda não alcançaram o nível de maturidade desejado para se combater em definitivo esses atos.

Nesse diapasão, no decorrer do presente artigo, pode-se constatar que o estudo da legitimidade das ações afirmativas frente a Constituição Federal, é um instrumento que contribui para garantir a efetivação da igualdade social, uma vez que os 
preceitos constitucionais analisados, juntamente com à relevância dos direitos fundamentais da dignidade da pessoa humana e da igualdade impõem a adoção de políticas públicas em favor das minorias marginalizadas, realizando assim uma transformação tão esperada socialmente.

Como sugestão para um trabalho futuro está em e acompanhar os avanços constitucionais correspondentes as ações afirmativas de todos os grupos considerados minoritários, mais principalmente, os avanços relacionados aos grupos LGBTQI, que atualmente, estão aumentando em quantidade de pessoas e demandas, razão pelo qual, faz-se necessário que o Poder Público inove para acompanhá-los em sua evolução, como também dos demais grupos desfavorecidos por uma sociedade, que embora esteja caminhando, ainda pode ser considerada retrógrada.

\section{Referências}

Araldi. Jr. I (2010) O princípio da igualdade como expressão dos direitos fundamentais do cidadão. In: Âmbito Jurídico, XIII, n. 82. http://www.ambitojuridico.com.br/site/?n_link=revista_artigos_leitura\&artigo_id=8414.

Azevedo, M. L. N de (2013) Igualdade e equidade: qual é a medida da justiça social? Revista da Avaliação da Educação Superior, 18(1), 129-150. http://www.scielo.br/scielo.php?pid=S141440772013000100008\&script=sci_abstract\&tlng=es

Barroso, L. R (2010) Curso de direito constitucional contemporâneo: os conceitos fundamentais e a construção do novo modelo. Saraiva.

Barroso, L. R (1987) Temas Atuais do Direito Brasileiro. Universidade do Estado do Rio de Janeiro, p. 91.

Bertoncini, M. E. S.N \& Filho. W. C de C. (2012) Políticas de ação afirmativa no contexto do direito constitucional brasileiro. Revista Eletrônica Direito e Política, Programa de Pós-Graduação Stricto Sensuem Ciência Jurídica da UNIVALI, 7(1), www.univali.br/direitoepolitica -ISSN 1980-7791

Bonavides, P. (2010) Curso de Direito Constitucional. (25a ed). Malheiros

Bardin, L (2011) Análise de conteúdo. Edições 70

Brasil. (1988) Constituição da República Federativa do Brasil. http://www.planalto.gov.br/ccivil_03/constituicao/ConstituicaoCompilado.htm

Brasil. Decreto 4.377, de 13 de setembro de 2002. Promulga a Convenção sobre a Eliminação de Todas as Formas de Discriminação contra a Mulher, de 1979.//www.planalto.gov.br/ccivil_03/decreto/2002/d4377.htm

Brasil. Decreto 65.810, de 8 de dezembro de 1969. Promulga a Convenção sobre a Eliminação de Todas as Formas de Discriminação Racial. http://legis.senado.gov.br/legislacao/ListaTextoIntegral.action?id=94836

Brasil (1969). Ministério da Justiça. Programa Nacional de Direitos Humanos.

Brasil. (2012) Supremo Tribunal Federal. Arguição de Descumprimento de Preceito Fundamental 186. Arguinte: Partido Democratas (DEM). Arguidos: Unb e outros. Relator: Ministro Ricardo Lewandowski. Brasília.

Brito filho, J.C. M. (2014) Ações afirmativas à luz da Constituição. Revista Jus Navigandi, Teresina, ano 19, n. 3915. https://jus.com.br/artigos/27001

Carmen Lúcia. Agência Brasil. diz que obrigatoriedade de vagas para deficientes está garantida na Constituição. http://agencia.brasil.jusbrasil.com.br/noticias/1004.

Cruz, Á. R de S. (2005) O direito à diferença: as ações afirmativas como mecanismo de inclusão social de mulheres, negros, homossexuais e pessoas portadoras de deficiência. (2a ed.) Del Rey.

Cruz, L. F. F. M. (2011) Ações afirmativas e o princípio da igualdade. Dissertação (Faculdade de Direito) - Universidade de São Paulo www.teses.usp.br/teses/.../Dissertacao_final_Luis_Felipe_Ferreira_Mendonca_Cru z.pdf

Demo, P. (2000) Metodologia do Conhecimento Científico. Atlas

Ferreira filho, M. G (2003). Aspectos jurídicos das ações afirmativas. Revista do Tribunal Superior do Trabalho, 69(2), 72-79.

Flick, U. (2009) Desenho da pesquisa qualitativa. Artmed.

Frischeisen, L. C. F. Políticas públicas (2000). A responsabilidade do administrador e o Ministério Público. Max Limonad.

Gil, A. C. (2008) Métodos e técnicas de pesquisa social. (6a ed.) Atlas, 10 p

Gil, A. C. (1994). Métodos e técnicas de pesquisa social. (4a ed). Atlas, 207 p

Gomes, J.B. B (2001) A recepção do instituto da ação afirmativa pelo direito constitucional brasileiro. Revista de Informação Legislativa, Brasília: Senado, ano 38(151), 129-152. 
Gomes, J. B. B (2001) Ação Afirmativa \& Princípio Constitucional da Igualdade: o direito como instrumento de transformação social. A experiência dos EUA. Renovar.

Gomes, J. B. B \& Silva, F. D.L. L da. (1999). As ações afirmativas e os processos de promoção da igualdade efetiva. Seminário Internacional - As Minorias e o Direito. 1999.

Lima, M. (2010) Desigualdades raciais e políticas públicas: ações afirmativas egoverno Lula. In: Novos Estudos - CEBRAP, 2010, 87, pp. 77-95. SALLES, Teresa. Raízes da desigualdade social na cultura política brasileira.

Mello, M. A. (2001) Ótica constitucional: a igualdade e as ações afirmativas. In: Tribunal Superior do Trabalho, Discriminação e Sistema Legal Brasileiro Seminário Nacional. Brasília: TST.

Menezes, P. L. (2001) A ação Afirmativa (affirmative action) no Direito Norteamericano. Revista dos Tribunais. 173p.

Moehlecke, S. (2002). Ação Afirmativa: História e debates no Brasil. Cadernos de Pesquisa. n. 117. http://www.scielo.br/scielo.php?script=sci_arttext\&pid=S0100-15742002000300011\&lng=pt\&tlng=pt

Mello, C. A. B de (1993) Princípio da Isonomia: Desequiparações Proibidas e Desequiparações Permitidas. Revista Trimestral de Direito Público p. 81/82

Piovesan, F. (2000) Direitos humanos e o direito constitucional internacional. (4ed) Max Limonad

Prudente, E A. J (2003) Experiências integradoras que o Brasil já conheceu: uma análise jurídica sobre a exclusão social dos afrodescendentes numa ordem constitucional integradora. In: Durham, Eunice R.; Bori, Carolina M. (Org.). Seminário:O Negro no Ensino Superior. São Paulo: Núcleo de Pesquisas sobre Ensino Superior.

Rabelo Jr. L. A. (2011) A justiça como equidade em Jonh Rawls. Âmbito Jurídico, Rio Grande, XIV, n. 94, http://www.ambitojuridico.com.br/site/index.php?n_link=revista_artigos_leitura\&artigo_id=10755

Rodrigues, E. B. Ações afirmativas nos EUA e sua legalidade no Brasil. Minas Gerais: Pontífica Universidade Católica de Minas Gerais, 2005. \&lt;http://www.fmd.pucminas.br/Virtuajus/1_2005/Discentes/PDF/Acoes\%20afirmativas\%20nos\%20eua\%20e\%20sua\%20legitimidade\%20no\%20brasil.pdf \&gt;

Rocha, C. L. A (1996) Ação afirmativa - O conteúdo democrático do Princípio da Igualdade Jurídica. Revista Trimestral de Direito Público, volume 15.

Rodrigues, E. B. (2005) Ações afirmativas nos EUA e sua legalidade no Brasil. Minas Gerais: Pontifica Universidade Católica de Minas Gerais\&lt; http://www.fmd.pucminas.br/Virtuajus/1_2005/Discentes/PDF/Acoes\%20afirmativas\%20nos\%20eua\%20e\%20sua\%20legitimidade\%20no\%20brasil.pdf\&gt;.

Roesler, Á da R. (2010) Princípio constitucional da igualdade e ações afirmativas. In: Âmbito Jurídico, Rio Grande, XIII, n. 77, jun. 2010. Disponível em: http://www.ambitohttp://www.ambito-juridico.com.br/site/index.php?n_link=revista_artigos_leitura\&artigo_id=7882juridico.com.br/site/index.php?n_link=re vis ta_artigos_leitura\&artigo_id=7882

Sarlet, Ingo Wolfgang. (2001) Constitucionalismo e democracia. Livraria do Advogado.

Santos, H. et al. (1999) Políticas públicas para a população negra no Brasil. ONU. [Relatório ONU].

Vieira, M. M. F. \& Zouain, D. M. Pesquisa qualitativa em administração. (2a ed.).

Vilas-Bôas, R. M. (2003) Ações Afimativas. Revista Jurídica Consulex, 163, 57-59.

Zimmermann, A. (2002) Curso de direito constitucional. Lúmen Juris, p. 138. 